\title{
Organizational Capability Deployment Analysis for Technology Conversion into Processes, Products and Services
}

\author{
Tomoe D. Hamanaka Gusberti', Claudia Viegas ${ }^{2}$, Márcia E. S. Echeveste ${ }^{3}$
}

\begin{abstract}
This article discusses Organizational Capabilities as the basic components of business models that emerged under the New Product Development Process and Technological Management. In the context of the new Technology Based Companies Development, it adopts a qualitative research in order to identify, analyze and underpin the organizational capability deployment in a process of technology conversion into product and service. The analysis was carried out considering concepts from literature review, in a technology based enterprise started by an academic spin-off company. The analysis enabled the elicitation of a Business Model and the discussion of their components, and correspondent evolution hypothesis. The paper provides an example of capability deployment accordingly the established theory illustrated by a case study. The study not just enumerate the needed partners, resources, customer channels, it enabled the description of their connection, representing the logic behind the decision made to develop the conceptual model. This detailed representation of the model allows better addressed discussions.
\end{abstract}

Keywords: organizational capability; capability based view; business model engineering; technology based companies

\footnotetext{
'Office of Technological Development - SEDETEC \& UFRGS' Science and Technology Park, Universidade Federal do Rio Grande do Sul - Brazil. E-mail: tomoe.gusberti@ufrgs.br

2Engineering and Knowledge Management Department, Universidade Federal de Santa Catarina - Brazil. E-mail: claudiav@egc.ufsc.br ${ }^{3}$ Industrial Engineering Post-Graduation Program \& Statistics Department, Mathematics Institute, Universidade Federal do Rio Grande do Sul - Brazil. E-mail: echeveste@producao.ufrgs.br
} 


\section{Introduction}

There are several investments to enable new technologies, but how to convert technology into new products, services and processes? New Product Development Process has been described as a Dynamic Capability in which Capabilities are linked and delinked in time to change the product, process and service basis of the company, to enable new products and consequently, new Business Models (Chesbrough \& Rosenbloom, 2002; Danneels, 2002; Eisenhardt \& Martin, 2000; Leonard-Barton, 1992). Hence, Business Model and Technological and Organizational Capabilities comprise some discussion trends in the Technology Management.

Every new product development effort should be coupled with the development of a business model which defines its 'go to market' and 'capturing value' strategies. The business model definition or engineering is a process to define a conceptual framework that embodies the organizational, operational, strategic and financial architecture of a business. The business model is originated and evolves from the interaction among managers, environment, customers, partners, investors and other economic actors, with the aim to obtain an effective and competitive organization (Amit \& Zott, 200I; Aoki \& Jackson, 2007; Chesbrough \& Rosenbloom, 2002; Doganova \& Eyquem-Renault, 2009; Glissman \& Sanz, 2009; Magretta, 2002; Morris, Schindehutte, \& Allen, 2005; Silverman, 1997; Teece, 2010).

Although several configuration elements for Business model are presented in the literature, the Organizational Capabilities are considered useful in the dynamic Environment context (Fleischer, Herm, \& Ude, 2007). This theoretical stream comprising the organizational Capabilities is presented as a promise for Technology Management, especially for New Technology-Based Companies acting in dynamic environments. The organization is considered a transitory repository of capabilities and routines, which are expressed through people, materials, technologies and other structures. Instead of considering opportunities as guide to the resource allocation definition, the capability development resource allocation process act as the determinant for the opportunity generation (Nooteboom, 2000). The organization evolves and is modified by reconfiguring its cpabilities and routines (Grant, 1996; Helfat \& Peteraf, 2003; Mathews, 2006; Nelson \& Winter, 1 982; Zahra, Sapienza, \& Davidsson, 2006). The evolutionary vision enables the discussion regarding how the nascent organizations evolves, through analyzing and interpreting the environment, to make decisions and learn (Aldrich \& Ruef, 2006; Mathews, 2006; Penrose, 1958; Stoelhorst, 2008).

The incorporation of organizational learning and Organizational Capabilities in the Business Model Literature, although enunciated as promising, is already not clear. The organiza- tions structures evolutions have been described by the $\mathrm{Ca}$ pability BasedView (CBV) as quasi-natural phenomenon: because its economical origin, the researchers (humans) have just observed and analyzed what happened, the companies are considered as black boxes. The business model literature brings a similar approach, presenting and classifying models. However organizations are artifacts and people make decisions to design it. To study an artificial phenomena one must comply about synthesis, not just analysis (Simon, 1996, 1997). Maybe for this reason the practical use of CBV can be described as limited, or just starting. The recent academic discussions point, for this reason, the need of going to the micro foundations of the organizational capabilities and discuss the proactive planning and development of organizational capabilities, linking the individual capabilities (competences) to the organizational capabilities (Felin \& Foss, 2009).

This work uses the business model and CBV concepts and contributes to the organizational capability micro foundations analyzing some related literature streams that present a capability deployment process for new technology based companies. The analysis performed uses the organizational capability concept, comprising a deployment of Organizational Capabilities for Business Model analysis for New Technology Based Companies Evolution. As consequence, the paper provides an example of capability deployment accordingly the established theory through a case study.

\section{Methodological considerations}

This paper adopts a qualitative research in order to identify, analyze and underpin the organizational capability deployment in a process of technology conversion into product and service in a new technology based company. The case study analysis was conducted considering the concepts obtained from literature review, in a technology based enterprise started by an academic spin-off company. The data source used for the analysis was documental analysis followed by the interaction of the researcher with the Company A's business manager. These interactions comprised four face meetings and several e-mail exchanges. The core problem in these interactions was related to understand how the business was organized, its objectives and concrete and planned ways to achieve them.

\section{Literature review}

The capability based management approach, considered as promise to be the theoretical ground of the technology management and the capability based planning, is one of the theoretical streams of the Evolutionary View of the Firms. It enables description and discussion on the dynamism of the new technology development and its conversion in products that modify the market structure, and induces the own 
firms' growth (Helfat, Finkelstein, \& Mitchell, 2007; Helfat \& Peteraf, 2003; Hite \& Hesterly, 200I; Lee, 2010; Nelson \& Winter, 1982). This approach is based on the organizational learning approach and is divergent from the best practices approach, although also complementary in several features (Voss, 1995). The capability based approach presents consonance with the process view in which business model configuration and evolution are based on value network creation. Although originated and inspired in its economic counterpart, the CBV has not focus in results, but rather in the internal processes of the organizations, as management problems, related with intervention (Nooteboom, 2000), hence, enabling a basis for planning. The main concepts applied in the organizational capabilities are resources, routines, and competences.

Resources are available inventory factors that the organization has, controls, or have access in the semi-permanent way to apply in its processes. They can be tangible or intangible (Helfat \& Peteraf, 2003). Some examples are: materials, know how that can be commercialized (patents and licenses), financial resources, physical resources (propriety, plants and equipments), human capital.

Routines are collections of organizational interactions, codified or not, with solution to actual problems. These interactions are inserted in the organizational memory and must be exercised to remain long lasting (Aldrich \& Ruef, 2006; Nelson \& Winter, 1982). This concept enables to integrate individual actions into collective level ones. Described organizational routines are stable even under extreme pressure. This stabilization is achieved through action alignment from one person to another, defining relative steady connections about situations and options for behavior. In a combined manner, it performs in the problem solution as a governance component (Becker, 2008). Repetitive standards or routines can also be defined as heuristics (Eisenhardt \& Martin, 2000; Helfat \& Peteraf, 2003; Nelson \&Winter, 1982; D. Teece, 1996). Routines are not necessarily formalized, monitored, managed or even noticed (implicit).

Capabilities enable the firm to deploy resources, usually in combination, to performing their activities. Organizational capabilities are high order organizational processes and comprise the abilities transformed in repetitive standards of activities, also called routines. Capabilities are developed through complex interactions between organizational tangible and intangible resources, and are time-consuming. They are based on information and knowledge development, as well as in the use and exchange between human capitals of the firm. They enable the analysis of individual's abilities and the social knowledge, and are defined by organizational principles, and through the way the intra and inter group, and inter-organizational relationships are organized (Amit \&
Schoemaker, 1993; Bingham, Eisenhardt, \& Furr, 2007; Kogut \& Zander, 1992).

Although largely discussed, the Capability Based View (CBV) related in literature is not clear about how to define and to develop capabilities. The Capability Engineering practice was presented as practicing and operationalization of Organizational Capabilities theory, but it is not yet applied either to the new technologies companies or as business model evolution tool. The Capability Engineering presents a prescriptive approach, focused on the managers' decision making. So, the integration of both practices can be useful in the planning and decision making processes in the companies. The more recent literature (Felin \& Foss, 2009) rescues the historical concepts of organizational (limited) rationality, and intentionality. It mentions the definition of capabilities as collective constructs to achieve specific goals, and that their effective development is influenced by several cognitive factors that define beliefs, behaviors and choices. For this reason, the authors argue about the need to pay attention to the micro-dynamics of capabilities development.

\section{Capability \& results}

The enterprise's business model is defined by the conjoint of the organizational capabilities and their interactions. These conjoint comprise a complex and organized structure to meet the aimed objectives and results, by definition, the visible components of capabilities. The logic behind capability definition as ability could come from results, because it is from results that the following features could arise: (i) manageability; and (ii) embedding of a causal chain of manageable abilities for an outcome achievement (to achieve a market need or a firm result). So, in order to clearly define the needed capability, it is necessary to clearly know how to fulfill objectives (expected outcomes) and how it is intended to obtain such ability (Amit \& Schoemaker, 1993; Day, 1994; Eden \& Ackermann, 2010; Helfat \& Peteraf, 2003; Nelson \& Winter, 1982). So, the capability is defined in a general and broad fashion, as an enterprise's macro-objective.

There are several possible candidate solutions to obtain the same capability, so, it must be roughly defined at the start, and defined gradually through the development, by successive information collection, analyzing and decision making. The company (or the group of companies) must define and conceptualize what they understand as adequate to each required capability. In the initial stage, the components must not be so tightly specified, because the Capability Based Planning has as principle to enable flexibility (Rouse \& Sage, 2007; Stevens, 1998).

Some authors use the repetition construct, calling the routines as basis for the capabilities (Felin \& Foss, 2009), but 
this paper considered also the primitive state of the organizational capabilities. Considering new enterprises, formal routines emerge just later moments of the enterprises' development, when the business model is becoming more defined and adjusted to the environment, while bringing stabilization. The primitive dynamic capabilities do not present routines, but experimentations for learning. In the context of entrepreneurship (the technological change promoter), the initiatives like experimentation and improvisation cannot be neglected. Hence, the relevance of spontaneous answers to problems and improvisation are taken in account. The experimentation uses previous experience and available information, the knowledge how (Baker, Miner, \& Eesley, 2003; Gong, 2005; Levinthal \& Rerup, 2006; Miner, Ciuchta, \& Gong, 2008). In the cognitive and behavioral analysis of organizational capabilities, the goals drive the collectives to enable the (primitive) capability by using organizational believes, and existing know-how. In this context, individuals are accounted to "explaining emergent outcomes" (Felin and Foss 2009, p. 162).

\section{Capability components}

The main components of the organizational capabilities are described by the four dimensions of Leonard-Barton (1992): knowledge and skills, technical systems, managerial systems, and values and norms. Capability Based Planning (CBP) from the Systems Engineering describes capabilities slightly different for industrial context (people, process products, technology, and facilities), and for the military context (doctrine, organization, training, material, education, people, and resources) (Davis, Shaver, \& Beck, 2008; Garvey, 2009; Stevens, 1998; Yue \& Henshaw, 2009).

The components become capabilities when the organization (company or enterprise) brings meaning to it, using and aligning it with the aim to add value for the commercial or industrial environment (Barney, Wright, Ketchen, \& others, 200 I; Eisenhardt \& Martin, 2000; Kazanjian \& Rao, 1999; Lavie, 2006; Rivkin, 2000; Sirmon, Hitt, \& Ireland, 2007). So, Market defines the target markets for the company's technologies, which it is supposed to be able to commercialize products and services derived from them. It is known that the technological capabilities can be applied to several purposes, industrial segments, and markets. In the initial stage, this definition can just represent some hypothesis, as emerging technologies have their potential application ill-defined (Cetindamar, Phaal, \& Probert, 20l0). It is also common the transference between industrial segments to revival some technological capability (or technology) that has already exhausted its potential in one industrial segment.
Result describes how the company delivers some value to the market(s) (customers and stakeholders), the visible component of the capability, and the objective of its deployment (Stevens, 1998; Yue \& Henshaw, 2009).

Capability comprises a definition of the capability, most likely starting with the word "ability".

Environment comprises the environmental factors that can represent a harness or an opportunity to the enterprise development. It comprises, for example, the national, regional and institutional innovation systems, and its innovation and technological development funding systems, incentives and laws.

Principles, culture, doctrine, norms and values are related to the organizational culture that promotes the interaction between people, and guides the decision taking. They are expressed and formalized as doctrines and norms, and implicit in organization shapes and structures, and have the common comprehension of the people that compose the company or institution. They also can be transferred to the new components by continuous interactions between the peoples by behavior, examples, attitudes and informal communication.

Knowledge-how comprises the "how to do" knowledge, being incorporated in the individual abilities of the people, routines of the processes, the structural command organization, and the existence of leaders that inspire and direct the people's actions. They are individual abilities sometimes possible to disseminate or to acquire through the formation of incorporation of experienced people (Loasby, 1998; Mota \& Castro, 2004). It can be deployed in: (i) routines and processes and (ii) People Centred Knowledge Resources: Ability, Leadership, Education \& Formation.

Resources are divided in technical systems and intangible resources or knowledge-that. Knowledge-that is expressed by knowledge contained in peoples and processes (documents and registers, for example) and can be acquired by training, or by specifying the formation (education) of the company's integrating peoples (Loasby, 1998; Mota \& Castro, 2004). It can be unfolded in (i) Training; (ii) information\& Data; (iii) People Centred Knowledge Resources: Education \& Formation. The Technical systems are essentially resources that were deployed by the capabilities in results and include products, technologies, facilities and materials. It can be divided in: (i) Material resources; (ii) Infrastructure, Facilities, Equipments, and Information Technology. 
Managerial systems optimize the knowledge-how, especially routines (or tasks or activities, routinized or not) and are supported or configure the company's or institution's organization, as hierarchical structure, information flow, decision making and prioritization logics or methods, for example.

\section{The enterprise $A$}

In this topic, the enterprise A case study exemplifies the capability definition. The enterprise and its constituents (enterprise' enabler companies) are described, followed by the application of the method. Both retrospective and prospective approaches were conducted during the analysis. The documental analysis allowed the initial evaluation, followed by the interaction of the researcher with the Company A's business manager to the improvement of the capability mapping. These interactions comprised four face meetings that totalized 270.32 minutes (medium of 67.58 minutes per meeting) and several e-mail exchanges. The results were analyzed and formalized by the researcher, using the meeting notes and audio records (Bryman, 2008).

The enterprise $A$ is placed in Brazil, and comprises four companies and one academic laboratory. The Firm A, an academic spin-off company created with the aim of converting the technology knowledge and intellectual property resulting from an academic research study, started the enterprise. This company is installed in a university technological incubator of the federal university in which the original academic research was conducted. The incubator offers some services to support the startup companies' development, including support to make a business plan. At the time of the analysis, the business plan was ready for a year.

The two founders of Firm $A$ are the main owners, and retain the intellectual property in association with the University. They consider important to maintain the interaction with the academic laboratory in which the research was originally conducted, being included as one of the components of the enterprise. The enterprise objectives the conversion and commercialization of the technology used to produce commercial products and services.

The Firm A's robot intellectual propriety can be applied to several situations. The founders decided to focus on petroleum and gas industry because they have some knowledge about this industry. The academic laboratory has carried out several applied researches with the interaction and funding of a big company from this industry.

At the time of the analysis, the management considered the product fully developed, but the service development was still in progress. They considered the business model to be roughly defined in terms of the enterprise's members and their roles. So, the enterprise was still defining the business model. Some alliances were still being to be defined, but was comprised by one equipment development company (company $A$ ), one inspection software development company (Company B), and one responsible for the contact with the client and to enable the human resource to execute inspections (company $\mathrm{C}$ ), beside the academic laboratory, that gave some technical support for the equipment development.

\section{Capabilities mapping from the business plan}

Initially is presented the first outline of the capabilities mapping resultant from a documental analysis of the Company A's business plan formalized in the company A website. The business plan enabled the identification of the following components categories: (i) intended markets; (ii) main desired results; (iii) organizational capabilities; (iv) principles, doctrines and culture; (v) routines, processes and managerial systems; and (vi) resources.

The main desired results identified were: (i) to provide technological inspection services for petroleum transformation chain; (ii) be recognized as a provider of technological services; (iii) to get developed an Equipment (Robotic Technology); (iv) financial growth; (v) Customers Satisfaction, with Inspection Procedures Efficiency, Safety for Customers, and deadline compliance; and (vi) to have contact and relationship with potential clients. These results and other components identified in the documental analysis are presented in the Figure I.

As expected, the main components easily identified from the business plan were market, results and values. Some intangible resources were mentioned in the business plan because the company A is a Technology Based Company and an academic spin-off: (i) contact with the original Research Laboratory, (ii) the qualified human capital represented by the previous researchers, and (iii) intellectual propriety.

The capabilities line was not filled while traditional business plan does not concern about them. The two references to the Routine/processes/managerial system line components are apparently because the company has a higher managerial maturity level than the usual academic spin-offs due to the business manager who is both founder's wife and an industrial engineer (and have a master degree in industrial engineering). These references are: a managerial system "innovative project management", and a best practice "multidisciplinary team to enable a team work favorable to generate new ideas".

It is also remarkable the amount of ideas identified as princi$\mathrm{ple/culture/value} \mathrm{line} \mathrm{component.} \mathrm{It} \mathrm{also} \mathrm{denotes} \mathrm{the} \mathrm{mana-}$ 
gerial maturity and the adequacy with a startup, in which formal procedures, routines or managerial systems cannot be applied.

The information from the business plan documental analysis were complemented by several interactions with the company A's business manager, mainly to identify capability components interactions. In this instance, the business manager apologized because the company's business plan was outdated, because several improvements were gotten from the business plan development, and because their frequency they were not able to update the information in the website.
This comment corroborates that the business plan is just a start for the business model development, and its evolution is a constant learning process, as indicated by the literature (Amit \& Zott, 200I; Doganova \& Eyquem-Renault, 2009; Teece, 2010).

\section{Detailed mapping}

The Figure 3 has been shown to the business manager, asking for complementation and for connections between the components. The bands in the diagram represent the component classes to be identified and interconnected. The dia-

\section{Capability Mapping}

from the Documental Analysis of the Company A's Business Plan
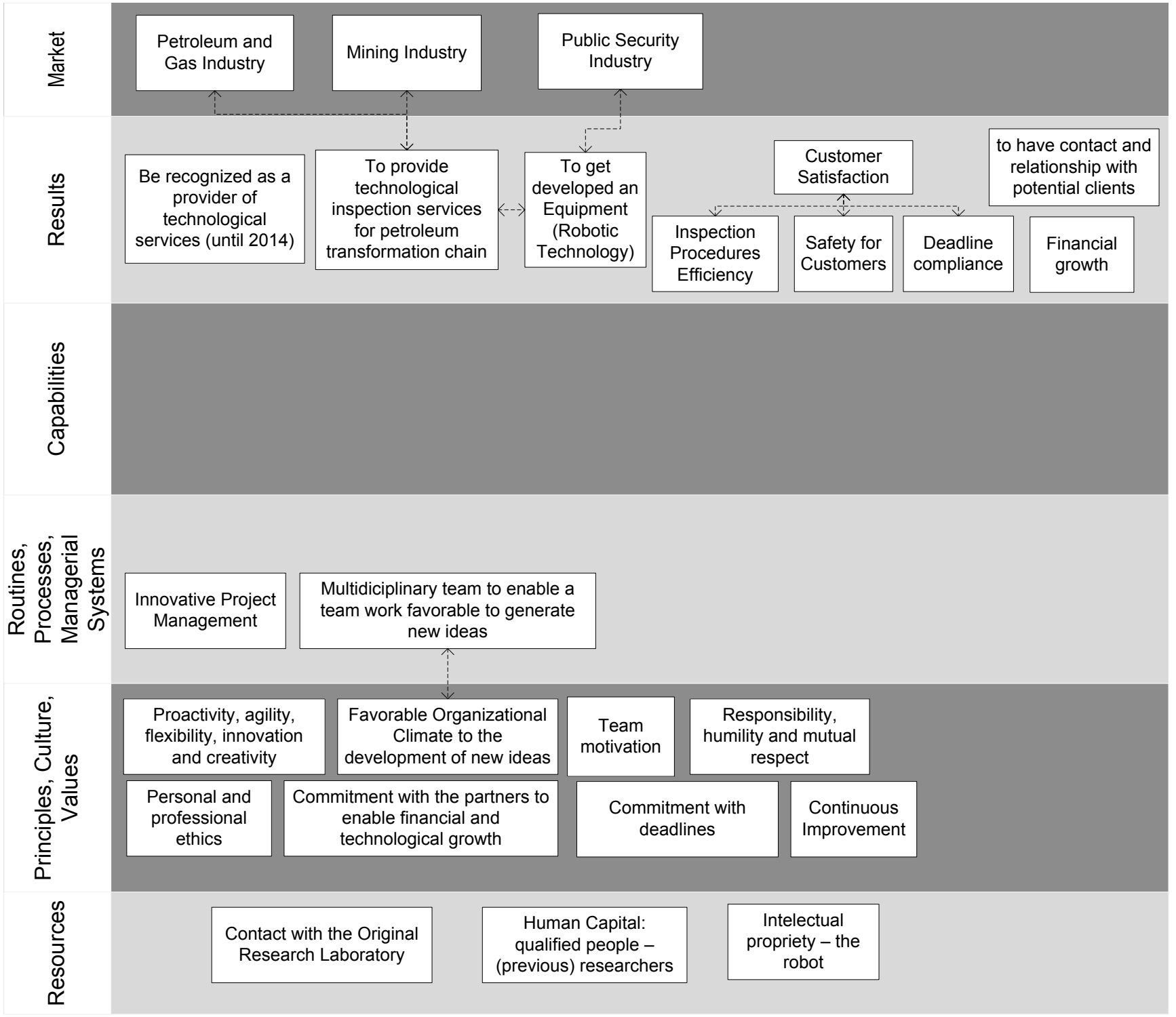

Figure I: Outline of Capability mapping obtained from the documental analysis of the business plan

ISSN: 07 I8-2724. (http://www.jotmi.org)

Journal of Technology Management \& Innovation @ Universidad Alberto Hurtado, Facultad de Economía y Negocios. 
gram enabled the representation of the complexity of the components interactions. Initially, the Market, result, capability and environment lines was filled, using the previous results. Specifically, (i) the results was connected to the capabilities, (ii) the desired results was connected to the target markets, and (iii) the environmental elements that can be considered opportunities to be seized by the capabilities or that represent barriers to be bypassed was also listed, although in this moment how to connect them to the other elements could not be defined. The effective connection of these environmental elements with the capability was possible only through the definition of routines (task, activities) to its deployment (Eden \& Ackermann, 20 I0; Felin \& Foss, 2009), obtained just by more detailed talk with the interviewee.

The improved map resultant from the interaction is presented in the Figure 5. The main capabilities identified were: (i) ability to develop technology; (ii) ability to manufacture/ assemble; (iii) ability to assure quality (precision, accuracy, calibration); (iv) ability to the relationship with the customer; (v) ability to provide the service; (vi) ability to sell services; (vii) ability to internal management; (viii) ability to attract investment; (ix) ability to manage the relationship with the partners; (x) ability to accountability; (xi) ability to training; (xii) ability to motivate the team.

The map (Figure 2) represents not just the company, but all enterprise, the structure to develop and provide technological services. The capabilities map enabled to illustrate the main desired results with needed capabilities. The companies' products and services are presented as results. Each color represents a specific enterprise member company or institution. The bicolored components occur just by the integration of two enterprise members. The map analyzes the enterprise without distinguishing the limits of companies. The dotted lines that delimitate graphical elements represent components not yet developed or obtained. Continuous lines delimited components indicate direct relationship or that is comprised in the capability. Connections represented by dotted line indicate influence, but the component does not comprise the capability.

The refining and deployment process was not linear, and sometimes required going back to the previously analyzed component classes. This dynamic approach encouragement was essential in the aim to obtain a complete refinement, as the interaction between the components is dynamic. The components were presented in the diagram as boxes connected directly or indirectly to the selected Market by delivering results.

A strong inclination to associate the capabilities with existing people was observed. It happens because capabilities can emerge initially in the individual level to become a routine just by time and use, as indicated in the literature (Felin \& Foss, 2009; Helfat \& Peteraf, 2003). When related to the permanent member of the organization, it will have no problem in associating the capability to a specific person, but if it is a temporary member, the capability can be lost. For this reason, efforts were carried out to disassociate the capabilities from the existing people, transcribing as at least their formation, training, or personal ability, and, when it is possible, converting it in a formalized routine or heuristics for controlling or decision making.

The results and capabilities line presented some intermediate results and intermediate capabilities. As the enterprise was in the definition stage, there are yet several components that are neither connected to the capabilities nor to the results.

During the deployment, it was shown useful the creation of a rule of connecting just capabilities to the results, and that all other components will be connected to capability just by routines. Other elements were connected to the capability only through the routines, because they are just resources to be deployed, transformed or used in the deployment by the capability.

With the domains understanding, the relevant practices was connected using the logics implicit on knowledge domains' principles (Arthur, 2010; Kogut \& Zander, 1992; Lall, 1992). When establishing these connections, values, norms and routines to use the technical systems (material resources) were defined. To coordinate these routines, more attention to the existing managerial systems was dedicated, or specific managerial processes or decision and optimization methods can be developed. But one interesting observation was that it was difficult to connect the previously identified value ideas to the routines. The use of managerial systems would enable it, but it was not obvious. For this reason, the figure detaches the line managerial systems, separating it from the routines and process lines.

For the managerial systems line, just project management routines were identified. A possible hypothesis, in the researcher opinion, it is because the managerial systems are usually developed just after the full development of the capability, when some level of control is needed. It was observed that this company has project management routines because it has in its composition an industrial engineer as business manager, and she know the relevance of some best practices, as project management practices and multidisciplinary team. She commented that the project management practices were implemented in the simplified manner in the way to not bring complexity to the process. This idea is consistent with the capability lifecycle literature, especially regarding stabilization for control (Helfat \& Peteraf, 2003). 


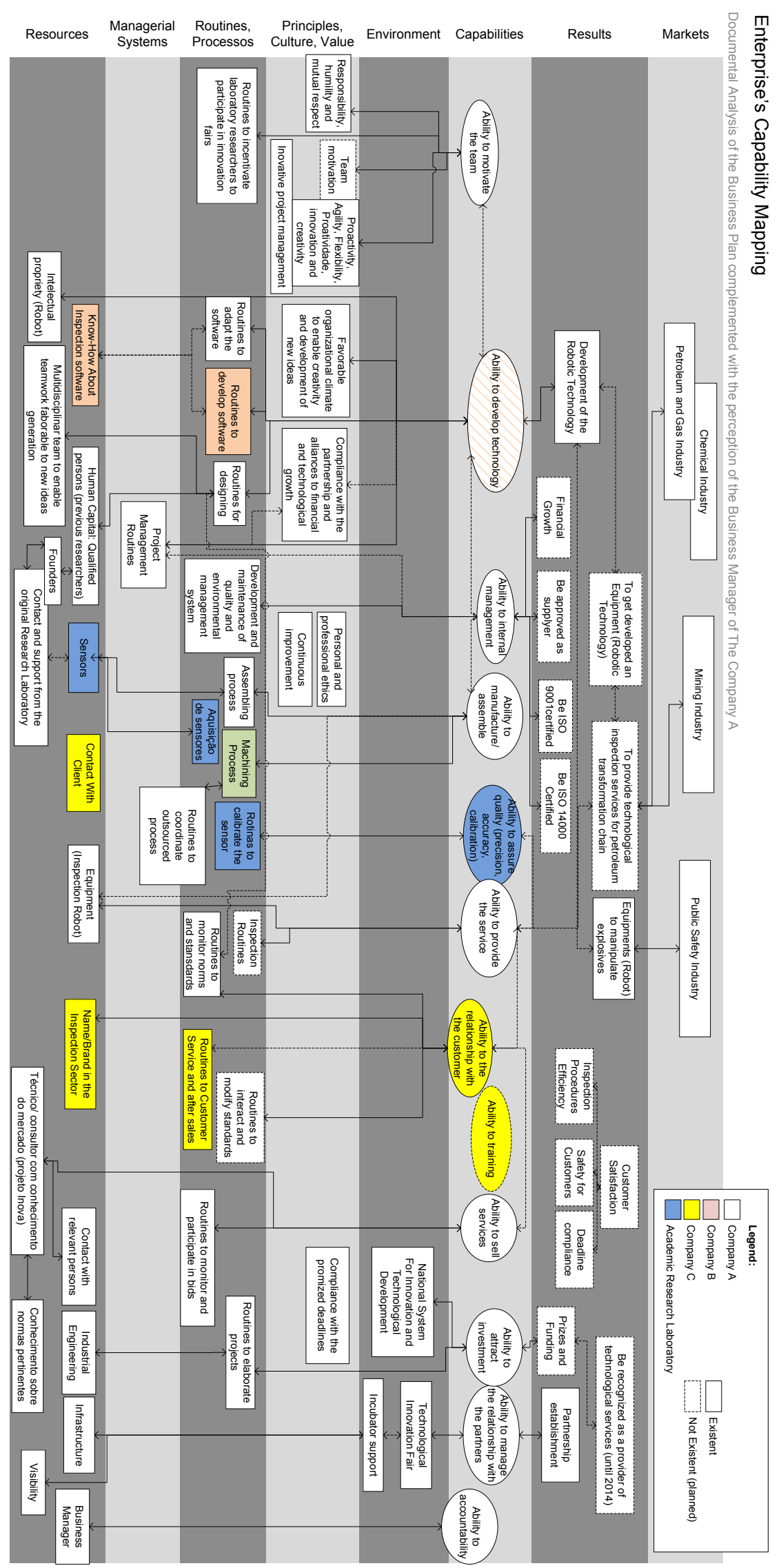

Figure 2: Improved Enterprise’s Capability Mapping 
Regarding the Principle/culture/value line, several components were not connected neither to routines, nor to managerial systems, because they were not planned to be obtained by some planned or systematic or formal manner. Several values appeared as goals or guidelines that are enunciated to all company to be followed by their members. In the researchers' perception, these value items appear not to be just in the intention level, but they used probably some other intangible or already indescribable behavioral or cognitive resources. The values appeared effectively merged in the culture of the firm, but possibly in the personal or individual manner, not planned, and without the intention to use some theoretical of practical basis. Due to the company A's small size and the founders' full time interaction with the company members, the elicitation of the guideline or goal appears effective.Another hypothesis is these culture or value components were inherited from the academic institution from where the majority of integrant of the company A come.

Some existing connections between components were not able to be mapped in the short time of the research. It was observed that spontaneous and detailed discussions were possible when focusing in more critical capabilities. It happens because companies must allocate attention firstly to more critical capabilities in its evolutional process. The elicitation of the meanings and connections to the unconnected components will enable better understanding of the organizational structure and its complexities, but the complete detailing was not intended in this work. Systemic mapping of the enterprises capabilities and its components is difficult to be drawn without segmentation. For this reason, capabilities must be defined and deployed in the isolated manner. In the next section, it is described how each capability were described and deployed for the enterprise A.

\section{Capabilities Deployment}

The previously described map (Figure 2) comprises just an outline of the enterprise's capabilities. It was easy to identify components just if the capability was already existent or if a known best practice to be implemented was identified. Some desired results were not connected to any components of existing capabilities. It means that there are capabilities that was in development stage and that the current configuration does not enable the achievement of these results. The "ability to provide service" capability is described in the sequence. This capability was selected because it was in development stage, in the moment of the analysis and the enterprise was allocating attention to its development.

During the capability deployment, firstly the objectives were identified. They are comprised by the (desired) result "inspection procedure efficiency" and other six results as shown in the Figure 3.To enable the deployment of this capability, it was considered relevant the state-of-the-art of the practices from the metrology knowledge dominium. Specifically, discussions related to the main best practices were made: (i) routines, systems and records to document the results in the aim to enable traceability to the results and reports; (ii) routines to calibration and other practices to assure measurement quality; and (iii) the use of standards. From this discussion, the routine "calibration" was refined. It were incorporated and connected to this routine the needs regarding the development and consolidation of the following components: (i) equipment maintenance and calibration records; (ii) equipment use records, with the aim to record the use in extreme environments (high temperatures, and corrosive vapors).

In this moment, the worries were not regarding control, monitoring or optimization of the capability, just its development by identification of components. Hence, the managerial systems line was joined with the resource/process line. The company has an intention to obtain ISO 900 I certification, because it was needed to act in specific markets. But the company was associating the ISO $900 \mathrm{I}$ certification process with the idea of rigidity due to formalization and control mechanism implantation, having some worries regarding it. It was discussed that ISO 900 I certification does not mean rigidity or excessive formalization, that this depends on the implantation and auditing process, and that a good auditor would not agree about the need of rigidity in a startup company acting in a dynamic technological sector.

The Figure 3 also enables to hypothesize that in development stage capabilities, there are little worries regarding principle, value or culture components. Components of this kind appeared in the previous figure just to compose the Technological development capability, a capability that was well developed and resulted in the intellectual propriety. Another reason for the company $A$ be conscious about them as best practices is because they have an industrial engineer as a member and have some support from the Incubator team. It is argued that these components are more related to managerial systems, and are not evidenced when the enterprise is just worried about achieving the results for the first time, but just when start to be worried about its longterm effectiveness.

Regarding resources, all resource classifications identified were used in this capability. In other capabilities analyzed (data not shown) occurred some resource classification lines without components. They were: training and material resources.

Another interesting observation was that the enterprise needed to change the market and the customer preferences. 
For example, the business manager mentioned a company that is targeted as the main customer for the enterprise. This company comprises a publicly traded joint stock Corporation and presents more than half of the shares belongs to the state, is considered a big company and is responsible for the majority of production in the petroleum and gas industry in Brazil. It has own standards and publishes norms to be accomplished by its suppliers. The business manager mentioned that some standards regarding automatized inspection must be changed with the aim to enable the enterprise to provide the service. The actual standard is adjusted to other technology and is so strictly defined in the manner that the designed service cannot accomplish the standard, although there is great potential to offer better results.

\section{Final considerations}

This work presented a capability deployment analysis that complied the following concepts: (i) capabilities are macro processes associated to enterprises results; (ii) capabilities are components for business model designing and engineering; (iii) the capability based approach for business model planning enables value adding chain comprehension; (iv) capabilities are comprised by a conjoint of routines; and (v) capabilities are planned in the prospective manner. The graphical resource enabled the business model's capability representation and deployment in an effective manner that enables to elucidate the causal chain of the capabilities components to achieve the desired results.

The capability development must be accomplished neither just about one company nor just about one enterprise, but regarding all the value chain, including customers and users routines to use the service or product and its results. The value focused deployment proposed enables the design of the more effective business model, defined as a way by which the company(ies) capture value by offering products and services. In this process, the understanding of how the value is perceived by the user as consequence of how they interact with the service and the product was shown essential. The consideration of the user actions enables not just embracing the all value chain, but also the identification of the need for environmental changes, as regarding products, services, operation and process standards, or even customer mind standards.

Business plan does not objective to explicitly identify the connections between the organizational components, as resources, capabilities and routines. The case shows that the method complements the traditional business planning practice, because business plan is not sufficient to detail the business model and usually does neither incorporate capabilities, routines, processes, nor managerial systems in the connected way to the desired results. These connections, for this reason, are usually implicit, and discussions regarding these connections and interactions are difficult to be conducted. Graphical representation has shown very interesting to enable discussions regarding business model hypothesis. So, it is possible to state that the analysis conducted enables complementation of the traditional business planning practice; and the Business Model elicitation for discussion of its components and evolution hypothesis. The traditional business plan comprises market, results and values. Hence, the business plan is just a start for the business model and traditionally does neither comprise organizational capabilities nor its components connections and interactions in a causal chain to enable results.

The analysis enabled Business Model elicitation for its components and evolution hypothesis discussion. The mapping process is shown useful for systemic enterprise planning, discussing the suitable business model obtaining. Especially in the environments that are not just dynamic, but also competitive, the capabilities development process must be a planned process, in which the components are articulated with the aim to compose the organizational capabilities. As a business model component, the conjoint of the needed organizational capabilities must be frequently revised, in a dynamic process.

The graphical representation has shown adequacy to the nonlinearity of the deployment process, and the complexity of the relations and interactions between the components to enable the capabilities. The graphical approach was easier to apply and to be understood, enabling very relevant discussions. The model not just enumerate the needed partners, resources, customer channels and so on, it enables the description of their connection, representing the logic behind the decision made to develop the conceptual model. This detailed representation enables better and oriented discussions.

The case study allowed the identification of some relevant contributions regarding how organizational capabilities can be planned, deployed and controlled during its development. But a simple case study does not enable generalization. For this reason, it is suggested a further research with the application of the method in more numerous cases, and considering the variability of technology based companies, regarding the dynamicity of the acting environments and markets, the companies development stages, their origins, cultural aspects and managerial team composition, the existent support from technology transfer offices, and original laboratory, Research Institute, and Company, for example. For further application in other cases, it is also suggested as future work the formalization and structuring of a method, comprising instructional procedures and some developments regarding quality in conducting the mapping process. 


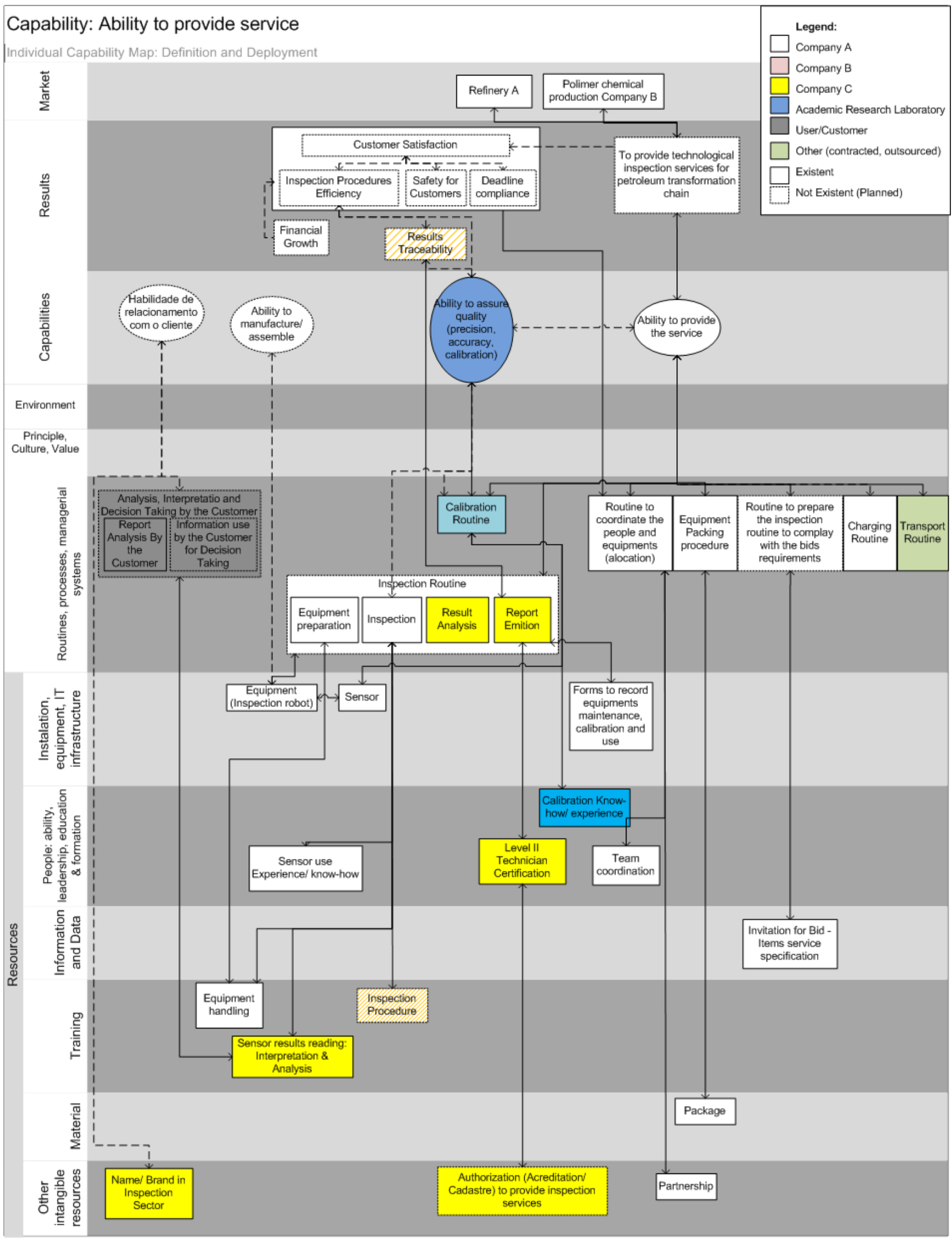

Figure 3: Deployment of the Capability "ability to provide service"

ISSN: 07 I8-2724. (http://www.jotmi.org)

Journal of Technology Management \& Innovation (c) Universidad Alberto Hurtado, Facultad de Economía y Negocios. 


\section{Acknowledgements}

This work comprises a result from a doctorate thesis financially supported by CNPq and CAPES.

\section{References}

ALDRICH, H., RUEF, M. (2006). Organizations Evolving (2nd ed., p. 330). London, UK: Sage Publications Ltd.

AMIT, R., SCHOEMAKER, P.J. H. (1993). Strategic assets and organizational rent. Strategic management journal, I4(I), 33-46. DOI: $10.1002 /$ smj.4250I40I05

AMIT, R., ZOTT, C. (200I).Value creation in E-business. Strategic Management Journal, 22(6-7), 493-520. DOI:10.1002/ smj. 187

AOKI, M., JACKSON, G. (2007). Understanding an emergent diversity of corporate governance and organizational architecture: an essentiality-based analysis. Industrial and Corporate Change, I7(I), I-27. DOI: 10.1093/icc/dtm037

ARTHUR, W. B. (2010). The Nature of Technology: What It Is and How It Evolves (p. 256). New York: Penguin Books, Limited.

BAKER, T., MINER, A. S., EESLEY, D. T. (2003). Improvising firms: bricolage, account giving and improvisational competencies in the founding process. Research Policy, 32(2), 255-276. http://dx.doi.org// 0.1016/S0048-7333(02)00099-9

BARNEY, J., WRIGHT, M., KETCHEN, D. J.. (200I). The resource-based view of the firm: Ten years after 1991. Journal of management, 27(6), 625-642. DOI: 10.1177/01492063010270060।

BECKER, M. C. (2008). Handbook of Organizational Routines (p. 343). Edward Elgar Publishing.

BINGHAM, C. B., EISENHARDT, K. M., FURR, N. R. (2007). What makes a process a capability? Heuristics, strategy, and effective capture of opportunities. Strategic Entrepreneurship Journal, I(I), 27-47. DOI: I0.1002/sej. I

BRYMAN, A. (2008). Social Research Methods (p. 748). Oxford University Press.

CETINDAMAR, D., PHAAL, R., PROBERT, D. (2010). Technology Management: Activities and Tools (p. 350). Palgrave Macmillan.
CHESBROUGH, H., ROSENBLOOM, R. S. (2002). The role of the business model in capturing value from innovation: evidence from Xerox Corporation's technology spin-off companies. Industrial and corporate Change, I I (3), 529-555.

DANNEELS, E. (2002). The dynamics of product innovation and firm competences. Strategic Management Journal, 23(I2), I095-I I II. DOI: 10.1002/smj.275

DAVIS, P., SHAVER, R., BECK, J. (2008). Portfolio-Analysis Methods for Assessing Capability Options. RAND (p. 203). Santa Monica, CA: RAND Corporation. Available at http:// oai.dtic.mil/oai/oai?verb=getRecord\&amp;metadataPrefix $=h$ tml\&amp;identifier=ADA477066. Last access: Sept., I4 2012.

DAY, G. S. (1994). The capabilities of market-driven organizations. The Journal of Marketing, 58(4), 37-52. Available: https://faculty.fuqua.duke.edu/ moorman/Marketing\%20 Strategy\%20Course\%20Materials/Day\%20-\%20The\%20Capabilities\%20of\%20Market-Driven\%20Organizations.pdf Last access: Sept I2th, 2012.

DOGANOVA, L., EYQUEM-RENAULT, M. (2009). What do business models do? Innovation devices in technology entrepreneurship. Research Policy, 38(10), 1559-1570. DOI:10.1016/j.respol.2009.08.002

EDEN, C., ACKERMANN, F. (20I0). Competences, Distinctive Competences, and Core Competences. In SANCHEZ, R., HEENE,A. (Eds.), A Focused Issue on Identifying, Building, and Linking Competences (Vol. 5, pp. 3-33). Emerald Group Publishing Limited.

EISENHARDT, K. M., MARTIN, J. A. (2000). Dynamic capabilities: what are they? Strategic management journal, $21(10-1 \mathrm{I})$, II05-II2I. DOI: 10.1002/1097-0266(200010/II)21:10/II<1105::AIDSMJI33>3.0.CO;2-E

FELIN, T., FOSS, N. J. (2009). Organizational routines and capabilities: Historical drift and a course-correction toward microfoundations. Scandinavian Journal of Management, 25(2), 157-167. DOI:10.1016/j.scaman.2009.02.003 DOI: http://dx.doi.org/10.1016/j.scaman.2009.02.003

FLEISCHER, J., HERM, M., UDE, J. (2007). Business Capabilities as configuration elements of value added networks. Production Engineering, Research and Development, 2(I), |87-192. DOI:I0.1007/s II740-007-00I2-I DOI: 10.1007/ sl 1740-007-0012-I

GARVEY, P. R. (2009). Analytical methods for risk management: a systems engineering perspective. Taylor \& Francis. 
GLISSMAN, S., SANZ, J. (2009). IBM Research Report A Comparative Review of Business Architecture. Architecture (Vol. I045I, p. 27). San Jose, CA, USA.

GONG, Y. (2005). The Dynamics of Routines and Capabilities in New Firms. In Academy of Management annual meeting (Vol. 53706, p. 38). Honolulu. Available at http://www. bus.umich.edu/Academics/Departments/CSIB/CSIB/Miner_03-II-05_Seminar_Paper.pdf

GRANT, R. (1996). Toward a knowledge-based theory of the firm. Strategic management journal, I7(Winter Special Issue), 109-122.

HELFAT, C. E., PETERAF, M.A. (2003). The dynamic resourcebased view: Capability lifecycles. Strategic Management Journal, 24(10), 997-1010. DOI: I0.1002/smj.332

HELFAT, C. E., FINKELSTEIN, S., MITCHELL,W. (2007). Dynamic Capabilities: Understanding Strategic Change in Organizations (p. 147). Wiley-Blackwell.

HITE, J. M., HESTERLY, W. S. (200I). The evolution of firm networks: from emergence to early growth of the firm. Strategic Management Journal, 286(3), 275-286. DOI: 10.1002/ smj.I56

KAZANJIAN, R. K., RAO, H. (1999). Research Note: The Creation of Capabilities in New Ventures--A Longitudinal Study. Organization Studies, 20(I), 125-142. DOI:10.1 I77/0170840699201006

KOGUT, B., ZANDER, U. (1992). Knowledge of the firm, combinative capabilities, and the replication of technology. Organization science, 3(3), 383-397. DOI: 10.1287/ orsc.3.3.383

LALL,S.(1992).Technological capabilities and industrialization. World Development, 20(2), I65-186. DOI:10.1016/0305750X(92)90097-F

LAVIE, D. (2006). Capability reconfiguration: an analysis of incumbent responses to technological change'. Academy of Management Review, 3I(I), I53-74. DOI: 10.5465/ AMR.2006.19379629

LEE, C.Y. (20I0). A theory of firm growth: Learning capability, knowledge threshold, and patterns of growth. Research Policy, 39(2), 278-289. DOI: 10.1016/j.respol.2009.12.008

LEONARD-BARTON, D. (1992). Core capabilities and core rigidities: A paradox in managing new product development. Strategic management journal, I3(SI), II I-I25. DOI: I0.1002/smj.4250131009
LEVINTHAL, D., RERUP, C. (2006). Crossing an Apparent Chasm: Bridging Mindful and Less-Mindful Perspectives on Organizational Learning. Organization Science, 17(4), 5025|3. DOI:10.1287/orsc.1060.0197

LOASBY, B. (1998). The organisation of capabilities. Journal of Economic Behavior \& Organization, 35(2), I39-160. DOI:I0.10I6/S0I67-268I(98)00056-0

MAGRETTA, J. (2002). Why business models matter. Harvard business review, 80(5), 3-8.

MATHEWS, J. A. (2006). Strategizing as Carried Out by Penrosean, Resource-Based Firms. In MATHEWS, J. A. (Ed.), Strategizing, Disequilibrium, and Profit (pp. 73-97). Stanford University Press.

MINER, A. S., CIUCHTA, M. P., GONG, Y. (2008). Organizational routines and organizational learning. In M. C. Becker (Ed.), Handbook of Organizational Routines (pp. 152-186). Cheltenham, UK: Edward Elgar.

MORRIS, M., SCHINDEHUTTE, M.,ALLEN, J. (2005). The entrepreneur's business model: toward a unified perspective. Journal of business research, 58(6), 726-735. DOI:10.1016/j. jbusres.2003.11.001

MOTA, J., CASTRO, L. M. De. (2004). A Capabilities Perspective on the Evolution of Firm Boundaries: A Comparative Case Example from the Portuguese Moulds Industry. Journal of Management Studies, 4I(2), 295-3 I6. DOI:I0.I I I I/ j. I 467-6486.2004.00433.x

NELSON, R. R.,WINTER, S. G. (1982). An evolutionary theory of economic change (p. 437). Harvard University Press.

NOOTEBOOM, B. (2000). Innovation, Entrepreneurship, and Competences. In B. Nooteboom (Ed.), Learning and Innovation in Organizations and Economies (pp. 52-74). New York: Oxford University Press.

PENROSE, E. (1958). The theory of the growth of the firm (Ist ed.). New York: Oxford University Press.

RIVKIN, J. (2000). Imitation of Complex Strategies. Management Science, 46(6), 824-844.

ROUSE,W. B., SAGE,A. P. (2007). Work , workflow and information systems. Information, Knowledge, Systems Management, 6, I-5. 
SILVERMAN, L. L. (1997). Organizational Architecture: A framework Successful Transformation. (P. F. Progress, Ed.) (pp. I-10). Partners for Progress. Available at http://www. partnersforprogress.com/articles/Organizational_Architecture.pdf

SIMON, H.A. (1996). The Sciences of the Artificial, 3rd Edition (p. 247). MIT Press.

SIMON, H.A. (1997).Administrative Behavior, 4th Edition (p. 384). Free Press.

SIRMON, D. G., HITT, M.A., IRELAND, R. D. (2007). Managing Firm Resources in Dynamic Environments to Create Value: Looking inside the Black Box. The Academy of Management Review, 32(I), 273-292. DOI: I0.5465/AMR.2007.23466005

STEVENS, R. (1998). Systems engineering: coping with complexity (p. 374). Pearson Education

STOELHORST, J. W. (2008). Why Is Management Not an Evolutionary Science? Evolutionary Theory in Strategy and Organization. Journal of Management Studies, 45(5), 10081023. DOI: 10.1 I I I/j. I 467-6486.2008.00774.x

TEECE, D. (1996). Firm organization, industrial structure, and technological innovation. Journal of Economic Behavior \& Organization, 3I(2), 193-224. DOI: 10.1016/S0I67$268 I(96) 00895-5$

TEECE, D. J. (2010). Business Models, Business Strategy and Innovation. Long Range Planning, 43(2-3), 172-194. DOI: 10.1016/j.Irp.2009.07.003

VOSS, C. a. (1995). Alternative paradigms for manufacturing strategy. International Journal of Operations \& Production Management, I5(4),5-I6.DOI: I0.I I08/0 I4435705 I06336 I I

YUE, Y., HENSHAW, M. (2009). An holistic view of UK military capability development. Defense \& Security Analysis, 25(I), 53-67. DOI: I0.1080/I475I790902749900

ZAHRA, S. A., SAPIENZA, H. J., DAVIDSSON, P. (2006). Entrepreneurship and Dynamic Capabilities :A Review , Model and Research Agenda. Journal of Management Studies, 43(4), 9|7-955. DOI: I0.1 I I I/j. I 467-6486.2006.006 I6.x 